\title{
The Prevalence of Diabetes and Prediabetes Among Elementary School Children in Birjand
}

\author{
Tayyebeh Chahkandi ${ }^{1}$; Fatemeh Taheri ${ }^{1, *}$; Toba Kazemi $^{1}$; Bita Bijari $^{1}$ \\ ${ }^{1}$ Department of Pediatrics, Birjand Atherosclerosis and Coronary Artery Research Center, Birjand University of Medical Sciences, Birjand, IR Iran \\ *Corresponding author: Fatemeh Taheri, Birjand Atherosclerosis and Coronary Artery Research Center, Pasdaran Avenue, Birjand University of Medical Sciences, Birjand, IR Iran, \\ E-mail:ftaheri64@yahoo.com
}

Received: December 15, 2013; Accepted: November 11, 2014

Background: Diabetes is associated with increased cardiovascular disease, mortality and morbidity.

Objectives: The present study aimed at assessing fasting blood sugar (FBS) in elementary school students in Birjand, 2012.

Materials and Methods: This cross-sectional and descriptive study was done on 1530 elementary school students who had been selected through multiple cluster sampling. FBS of these students was tested applying the enzymatic process. The obtained data was analyzed by means of SPSS software(V15) and statistical tests t and $X^{2}$.

Results: In this study, 833 girls and 697 boys were evaluated. Mean FBS of the whole study population was $86.9 \pm 8.8 \mathrm{mg} / \mathrm{dL}$; FBS was higher in boys compared to girls. FBS of 1453 (95\%) children was $<100 \mathrm{mg} / \mathrm{dL}$, the mean being $85.8 \pm 6.8 \mathrm{mg} / \mathrm{dL}$. FBS of 698 (45.6\%) students of the above population was $86-99 \mathrm{mg} / \mathrm{dl}$. It was $100-125 \mathrm{mg} / \mathrm{dL}$ in $72(4.7 \%)$ individuals. Five (0.3\%) students had FBS $>126 \mathrm{mg} / \mathrm{dL}$. Mean FBS increased in proportion to age, which was statistically significant.

Conclusions: Although the prevalence of diabetes is not considerable; however, based on the relatively high portion of those children with high degree of blood glucose in the range in which the risk of diabetes and prediabetes in the following years rises dramatically, the need for further care of health authorities, an extensive screening activity, and undertaking intervening measures to prevent the epidemic of diabetes and consequently cardiovascular disease is emphasized.

Keywords: Diabetes Mellitus; Prediabetic State; Blood Glucose; Child

\section{Background}

It is certain that the main cause of cardiovascular diseases (CVD) backs to early childhood (1-4). Impairment in the metabolism of carbohydrates leads to increased mortality and morbidity of cardiovascular diseases (5). The number of type II diabetic patients is increasing in the world, and many of them remain undiagnosed. The cardiovascular risk of undiagnosed diabetes is the same or higher than the previously diagnosed ones (6). Metabolic syndrome is a set of major risk factors for CVD with high blood glucose being one of them (7-10). Obesity, particularly central obesity is associated with insulin resistance (10-12). During recent decades, the prevalence of obesity in children is increasing and it is expected that impairment in carbohydrate metabolism would be more prevalent $(8,9,13)$. Therefore, identifying children susceptible to abnormal carbohydrate metabolism, which has a decisive role in CVD or diabetes, is of vital importance (14).

Those persons having impaired fasting glucose (IFG) and/or impaired glucose tolerance (IGT), who are at higher risk of diabetes, are called "prediabetics" (15-17).
A "prediabetic" state is an intermediary and returnable condition of carbohydrate metabolism disorder before getting diabetes II (18). In other words, IFG and IGT are intermediate stages of disordered carbohydrate metabolism between normal glucose homeostasis and diabetes (15). Identifying children at risk and taking intervening measures can have an effective role in preventing CVD and reducing long-term mortality and morbidity (19).

\section{Objectives}

Regarding that there was no documented data on blood glucose of Birjandi children, the present study aimed at determining the prevalence of diabetes and prediabetes of this population.

\section{Materials and Methods}

This cross-sectional and descriptive study was done on 1530 elementary students aged 6-11 years. Proportional multiple cluster method was applied for choosing the samples. According to the socioeconomic levels, Birjand 
city is divided into five regions. In following, state-run elementary schools of each region as well as private schools were evaluated. Considering the distribution of schools in different districts of the city, 10 elementary schools for girls and boys were selected. Then, with respect to the population of the respective school and the class, a number of students were chosen from each class. Based on the above procedure, 1700 students were chosen and a demographic questionnaire together with a consent form was sent to their parents. The parents were asked to fill the questionnaire and the consent forms at home and return it to the school. We received 1530 completed questionnaires. According to the plan, the students were referred to a diagnostic clinic where a blood sugar sample after a 12-hour fasting was taken from each individual. The obtained samples were immediately centrifuged and sugar levels determined through enzymatic procedure using German Rosh kits. The standard by which impairment in FBS would be identified was that of ADA, i.e. FBS $\geq 100$ $\mathrm{mg} / \mathrm{dL}$, but $<125 \mathrm{mg} / \mathrm{dL}$. FBS $\geq 126 \mathrm{mg} / \mathrm{dL}$ was accounted for diabetes (20). Statistical analysis was performed by means of SPSS software (v: 15) and comparison of qualitative variables was made using $\mathrm{X}^{2}$; and prevalence was mentioned in percentage, $\alpha \leq 0.05$ was taken as the significant level.

\section{Results}

The elementary students studied consisted of 1530 cases; 833 (54.4\%) girls and 697 (45.6\%) boys. Mean age of the children was $9.1 \pm 1.4$ years. The age range was 6 to 11.9 years. Mean FBS of the whole population was $86.9 \pm$ $8.8 \mathrm{mg} / \mathrm{dL}, 87.9 \pm 7.6 \mathrm{mg} / \mathrm{dL}$ in boys and $86.1 \pm 9.6 \mathrm{mg} / \mathrm{dL}$ in girls and this difference was statistically significant ( $P<0.001$ ) (Table 1). Prevalence of diabetes was $0.3 \%$ (i.e. $0 \%$ in males and $0.6 \%$ in females) and Prevalence of prediabetes was $4.7 \%$ (i.e. $5.5 \%$ in males and $4.1 \%$ in females).
In 1453 (95\%) cases including 794 (95.3\%) of girls and 659 (94.3\%) of boys, FBS was $<100 \mathrm{mg} / \mathrm{dL}$ (mean: $85.8 \pm 6.8$ ). FBS of $95 \%$ of the students in this group was $79-92.7 \mathrm{mg} /$ dL, i.e. FBS of 755 (49.3\%) cases was $<86 \mathrm{mg} / \mathrm{dL}$ and that of 698 (45.6\%) individuals was $86-99 \mathrm{mg} / \mathrm{dL}$. In $72(4.7 \%)$ subjects of the whole population, including 34 (4.1\%) of females and 38 (5.5\%) of males whose mean age was 9.3 years, FBS was 100-125 mg/dL which was not statistically significant (Table 2).

Relationship between age and prevalence of diabetes and prediabetes was not significant, nor in girls neither in boys (Table 2 ). Among the students, 5 (0.3\%) girls whose mean age was 9.8 years had an FBS $>126 \mathrm{mg} / \mathrm{dL}$ (mean: $151.8 \pm 15.4)$. Mean FBS in the whole population was proportional to age, which was statistically significant $(\mathrm{P}<$ 0.001). Figure 1 shows mean and 95\% CI of mean FBS accounting for age and sex.

Table 1. Mean Fasting Blood Glucose in Our Subjects for Age and Sex ${ }^{\text {a }}$

\begin{tabular}{cccc}
\hline & Males & Females & P Value \\
\hline Age, yr & & & \\
\hline 6 & $85.94 \pm 6.84$ & $83.40 \pm 8.28$ & 0.05 \\
7 & $85.55 \pm 7.70$ & $83.46 \pm 11.45$ & 0.07 \\
\hline 8 & $87.55 \pm 7.28$ & $85.22 \pm 7.73$ & 0.006 \\
9 & $88.76 \pm 7.75$ & $87.10 \pm 8.94$ & 0.08 \\
10 & $89.42 \pm 7.20$ & $88.92 \pm 7.270$ & 0.6 \\
\hline 11 & $90.68 \pm 7.59$ & $87.24 \pm 11.26$ & 0.006 \\
\hline Total & $87.99 \pm 7.60$ & $86.13 \pm 9.65$ & $<0.001$ \\
\hline
\end{tabular}

${ }^{\mathrm{a}}$ Data are presented as mean $\pm \mathrm{SD}$.

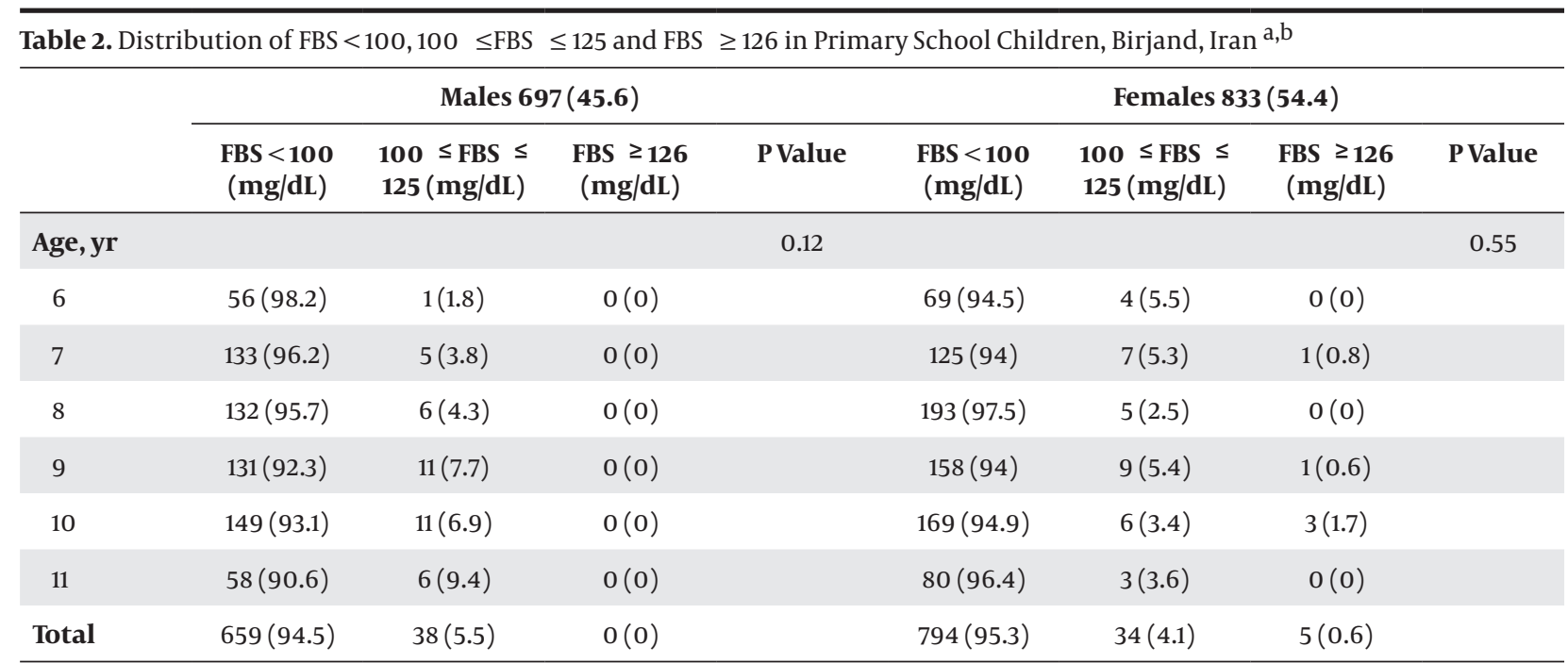

a Abbreviations: FBS, fasting blood sugar.

b Data are presented as No.(\%). 


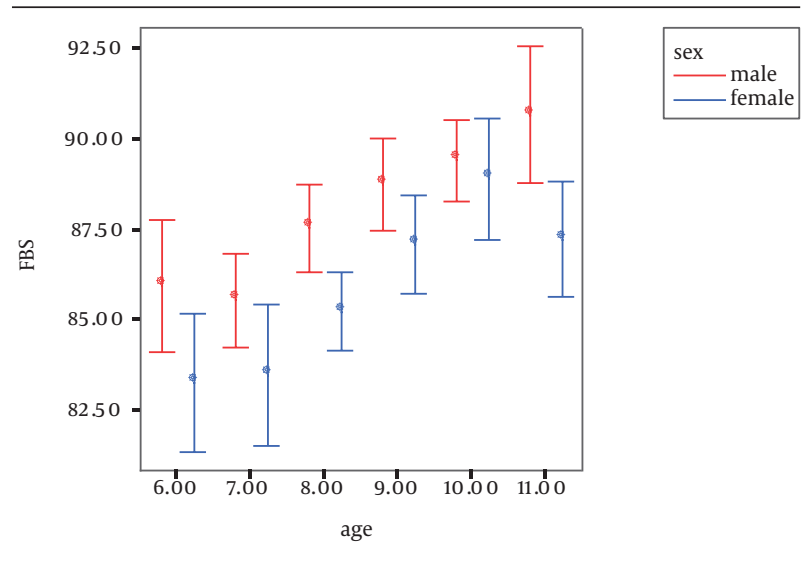

Figure 1. Comparison of Mean FBS for Age and Sex

\section{Discussion}

As seen in the present study, in the majority (95\%) of cases - based on ADA criteria - FBS was within normal range, which is similar to the results of Nguyen's study (20). A prospective study by Nguyen et al., too, revealed that blood glucose level was mostly within normal range with a mean of $84.6 \mathrm{mg} / \mathrm{dL}$ (20). Although impairment in FBS which leads to diabetes, is not of high prevalence in the present study, $45.6 \%$ of those with normoglycemic state had an FBS between $86-99 \mathrm{mg} / \mathrm{dL}$; a condition which must be paid special attention to, since it covers those being at risk. Different studies indicate that high FBS, within normal range, can more dependently than other cardio metabolic factors predispose children to a diabetic condition (i.e. prediabetic state or diabetes II) during early adulthood (18, 20, 21).

The prospective study by Nguyen et al. revealed that children with FBS 86-99 mg/dL, even after controlling of other cardio metabolic factors, are significantly (i.e. more than two times) at the risk of a pre-diabetic condition and diabetes during adulthood compared with children with FBS less than $86 \mathrm{mg} / \mathrm{dL}$ (20). In Bogalusa heart study, it was found that adults with IGT or those having diabetes II had a higher FBS from childhood to adulthood, compared to adults who had normal FBS (22). O'Malley et al. indicated that those with an FPG level between 90 and $100 \mathrm{mg} / \mathrm{dL}$ had an increased risk of developing diabetes (22). The case-control study conducted in patients with premature acute myocardial infarction in Birjand City by Kazemi et al. found that mean blood glucose was significantly higher in the premature myocardial infarction than in the controls (122.6 vs.86.3 mg/dL, $\mathrm{P}=0.001)(23)$.

Also, in patients with premature myocardial infarct, blood glucose $>100 \mathrm{mg} / \mathrm{dL}$, as one of the components of metabolic syndrome, was significantly higher than in the controls (30.6\% of patients vs $14.3 \%, \mathrm{OR}=2.65$ (5.4-1.3), $\mathrm{P}=$ 0.006 ) (24). Another study conducted on stroke patients by Dehghani Firoozabadi et al. showed a high (14.9\%) prevalence of diabetes in these patients (25). According to our and other studies $(18,26)$ mean FBS of boys was higher, this causes them to be at higher risk for a prediabetic condition. The underlying mechanism of this problem is not yet known (18). Central obesity is a risk factor to insulin resistance and to diabetes II. Puberty is associated with drastic changes in size, shape, and composition of the body. While girls have higher total body fat percentage during puberty, boys suffer more from central obesity (18).

Our study showed that girls' FBS reached its peak at about the age of 10, but it suddenly declined afterward; however, on the other side, boys' FBS showed the monotonic increase all over the range of ages in this study (Figure 1). The variation in blood glucose level at different ages and in both sexes is associated with pre and post pubertal hormonal changes (27).

Herein, we found the trend of FBS increasing in both sexes up to age 11-14 years. This increase in FBS is attributed to the child's growth and multiple hormonal changes effective on different metabolic patterns. Moreover, the effect of estrogen and androgen on carbohydrate metabolism and on serum lipoproteins has been confirmed by other investigators. Proneness to decrease FBS around the time of puberty is probably due to the effect of sex and/or growth hormones on carbohydrate metabolism $(28,29)$. Regarding that diabetes complications such as nephropathy and retinopathy are proportionate to the duration of diabetes, early diagnosis and proper control of high FBS in normoglycemic range during childhood and puberty can effectively prevent the incidence of diabetes II or postpone it to the end of lifespan (18). Although the present study shows that the population of children with FBS impairment and diabetic children is not significant, the relatively high percentage of children with high FBS but within normal limit can be predictive of following risk for developing diabetes during youth, middle age, and old age.

This is a warning and can, as a principle element of metabolic syndrome, increase the probability of the problem and be an important factor in the epidemic of CVD during following years. In order to study the final outcome of children's FBS impairment, prospective researches are required. The results of the present study can be used as a basis in following studies. In summery, some of the most important factors affecting reduction of long-term morbidity and mortality are screening and assessing of children at risk, then identifying precursors and controlling them, correcting life style and nutrition of children, periodic later studies, and warning families and state health planners.

Some limitations to the present study were:

1. The study was cross-sectional

2. Because of the unavailability of information about nutrition and economic status of the subjects, determining the extent of influence of above factors on FBS was not possible.

Although for detecting abnormal carbohydrate metab- 
olism, IGT test is a better test than FBS, its application to such a large population of children to be screened was not possible. Also ADA, because of this problem, recommend FBS to diagnose diabetic cases.

\section{Acknowledgements}

The authors feel themselves obliged to the research assistant of BUMS for accepting their plan and funding the project. They also thank the authorities of Birjand Educational Office and all the students who took part in the study. We express our gratitude to Mr. Hossein Nasrabadi and other coworkers for lab preparations and helping in data collection.

\section{References}

1. Rodrigues AN, Abreu GR, Resende RS, Goncalves WL, Gouvea SA Cardiovascular risk factor investigation: a pediatric issue. Int $J$ Gen Med. 2013;6:57-66.

2. Laitinen TT, Pahkala K, Magnussen CG, Viikari JS, Oikonen M, Taittonen L, Mikkila V, Jokinen E, Hutri-Kahonen N, Laitinen T, Kahonen M, Lehtimaki T, Raitakari OT, Juonala M, et al. Ideal cardiovascular health in childhood and cardiometabolic outcomes in adulthood: the Cardiovascular Risk in Young Finns Study. Circulation. 2012;125(16):1971-8.

3. Hartiala O, Magnussen CG, Kajander S, Knuuti J, Ukkonen H, Saraste A, Rinta-Kiikka I, Kainulainen S, Kahonen M, Hutri-Kahonen N, Laitinen T, Lehtimaki T, Viikari JS, Hartiala J, Juonala M, Raitakari OT, et al. Adolescence risk factors are predictive of coronary artery calcification at middle age: the cardiovascular risk in young Finns study. J Am Coll Cardiol. 2012;60(15):1364-70.

4. Kamphuis CB, Turrell G, Giskes K, Mackenbach JP, van Lenthe FJ. Socioeconomic inequalities in cardiovascular mortality and the role of childhood socioeconomic conditions and adulthood risk factors: a prospective cohort study with 17-years of follow up. BMC Public Health. 2012;12:1045.

5. Matheus AS, Tannus LR, Cobas RA, Palma CC, Negrato CA, Gomes MB. Impact of diabetes on cardiovascular disease: an update. Int J Hypertens. 2013;2013:653789.

6. Hadaegh F, Bozorgmanesh MR, Ghasemi A, Harati H, Saadat N, Azizi F. High prevalence of undiagnosed diabetes and abnormal glucose tolerance in the Iranian urban population: Tehran Lipid and Glucose Study. BMC Public Health. 2008;8:176.

7. Bouzas I. Metabolic syndrome during adolescence. Adolesc Saude. 2011;8(3):54-62.

8. Chen F, Wang Y, Shan X, Cheng H, Hou D, Zhao X, Wang T, Zhao D, $\mathrm{Mi}$ J, et al. Association between childhood obesity and metabolic syndrome: evidence from a large sample of Chinese children and adolescents. PLoS One. 2012;7(10).

9. Han JC, Lawlor DA, Kimm SY. Childhood obesity. Lancet. 2010; 375(9727):1737-48.

10. Afkhami-Ardekani M, Zahedi-Asl S, Rashidi M, Atifah M, Hosseinpanah F, Azizi F. Incidence and trend of a metabolic syndrome phenotype among Tehranian adolescents: findings from the Tehran Lipid and Glucose Study, 1998-2001 to 2003-2006. Diabetes Care. 2010;33(9):2110-2.

11. Weiss R, Dziura J, Burgert TS, Tamborlane WV, Taksali SE, Yeckel CW, Allen K, Lopes M, Savoye M, Morrison J, Sherwin RS, Caprio S, et al. Obesity and the metabolic syndrome in children and adolescents. N Engl J Med. 2004;350(23):2362-74.
12. Steinberger J, Daniels SR, American Heart Association Atherosclerosis H, Obesity in the Young C, American Heart Association Diabetes $\mathrm{C}$. Obesity, insulin resistance, diabetes, and cardiovascular risk in children: an American Heart Association scientific statement from the Atherosclerosis, Hypertension, and Obesity in the Young Committee (Council on Cardiovascular Disease in the Young) and the Diabetes Committee (Council on Nutrition, Physical Activity, and Metabolism). Circulation. 2003;107(10):1448-53.

13. Taheri F, Kazemi T. Prevalence of Overweight and Obesity in 7 to 18 Year-old Children in Birjand/Iran. Iran J Pediatr. 2009;19(2):135-40.

14. Morrison JA, Glueck CJ, Wang P. Childhood risk factors predict cardiovascular disease, impaired fasting glucose plus type 2 diabetes mellitus, and high blood pressure 26 years later at a mean age of 38 years: the Princeton-lipid research clinics follow-up study. Metabolism. 2012;61(4):531-41.

15. Craig ME, Hattersley A, Donaghue KC. Definition, epidemiology and classification of diabetes in children and adolescents. Pediatr Diabetes. 2009;10 Suppl 12:3-12.

16. American Diabetes A. Diagnosis and classification of diabetes mellitus. Diabetes Care. 2012;35 Suppl 1:S64-71.

17. Unwin N, Shaw J, Zimmet P, Alberti KG. Impaired glucose tolerance and impaired fasting glycaemia: the current status on definition and intervention. Diabet Med.2002;19(9):708-23.

18. Wang G, Arguelles L, Liu R, Zhang S, Brickman WJ, Hong X, Tsai HJ, Wang B, Xing H, Li Z, Xu X, Wang X, et al. Tracking blood glucose and predicting prediabetes in Chinese children and adolescents: a prospective twin study. PLoS One. 2011;6(12).

19. Prasad AN. Type 2 diabetes mellitus in young need for early screening. Indian Pediatr. 2011;48(9):683-8.

20. Nguyen QM, Srinivasan SR, Xu JH, Chen W, Berenson GS. Fasting plasma glucose levels within the normoglycemic range in childhood as a predictor of prediabetes and type 2 diabetes in adulthood: the Bogalusa Heart Study. Arch Pediatr Adolesc Med. 2010;164(2):124-8.

21. Nguyen QM, Srinivasan SR, Xu JH, Chen W, Kieltyka L, Berenson GS. Utility of childhood glucose homeostasis variables in predicting adult diabetes and related cardiometabolic risk factors: the Bogalusa Heart Study. Diabetes Care. 2010;33(3):670-5.

22. O'Malley G, Santoro N, Northrup V, D'Adamo E, Shaw M, Eldrich S, Caprio S, et al. High normal fasting glucose level in obese youth: a marker for insulin resistance and beta cell dysregulation. Diabetologia. 2010;53(6):1199-209.

23. Kazemi T, Sharifzadeh GR, Zarban A, Fesharakinia A, Rezvani MR, Moezy SA. Risk factors for premature myocardial infarction: a matched case-control study. J Res Health Sci. 2011;11(2):77-82.

24. Kazemi T, Sharifzadeh G, Zarban A, Fesharakinia A. Comparison of components of metabolic syndrome in premature myocardial infarction in an Iranian population: a case -control study. Int JPrev Med. 2013;4(1):110-4.

25. Dehghani Firoozabadi M, Kazemi T, Sharifzadeh G, Dadbeh S, Dehghan P. Stroke in birjand, iran: a hospital-based study of acute stroke. Iran Red Crescent Med J. 2013;15(3):264-8.

26. Barzin M, Hosseinpanah F, Saber H, Sarbakhsh P, Nakhoda K, Azizi F. Gender Differences Time Trends for Metabolic Syndrome and Its Components among Tehranian Children and Adolescents. Cholesterol. 2012;2012:804643.

27. Chahkandi T, Taheri F, Bijari B, et al. . Prevalence of high normal FBS and prediabetes among adolescents in Birjand, East of Iran, 2012. J Educ Health Promot.;[In Press].

28. Tfayli H, Arslanian S. The challenge of adolescence hormonal changes and sensitivity to insulin. Diabetes Voice . 2007;52(special issue):28-30.

29. Goran MI, Gower BA. Longitudinal study on pubertal insulin resistance. Diabetes. 2001;50(11):2444-50. 